\title{
Food Effect Study
}

National Cancer Institute

\section{Source}

National Cancer Institute. Food Effect Study. NCI Thesaurus. Code C98729.

Studies that are conducted to assess the effect of food on the rate and extent of absorption of a drug, either compared to a fasted state or to a reference drug. 